\title{
Neutron diffraction investigations on residual stresses contributing to the fatigue crack growth in ferritic steel tubular bridges
}

\author{
C. Acevedo ${ }^{\mathrm{a}, *}$, A. Evans ${ }^{\mathrm{b}}$, A. Nussbaumer ${ }^{\mathrm{a}}$ \\ a ICOM Steel Structures Laboratory, EPFL Swiss Federal Institute of Technology, CH-1015 Lausanne, Switzerland \\ ${ }^{\mathrm{b}}$ Institut Laue-Langevin, F-38042 Grenoble, France
}

\section{A R T I C L E I N F O}

\section{Article history:}

Received 16 December 2010

Received in revised form

12 April 2012

Accepted 5 May 2012

\section{Keywords:}

Welding

Neutron neutron

Residual stresses

Steel

Fatigue

\begin{abstract}
A B S T R A C T
Fatigue crack growth observed in tubular K-joint specimens, typical of tubular bridge structures, always initiates at the chord crown toe locations whether the applied stress range is tensile or compressive. Even though other locations around the weld have highest hot-spot stresses, chord crown toe locations are still the most critical. This raises the question about the relevant tensile residual stress level at that location. The results of residual stress investigations, obtained using neutron diffraction measurements highlight that the direction and location of the maximum tensile residual stresses in K-joints is substantially different from those in the more usual tubular butt joints. Indeed, it is shown that the highest tensile residual stresses are oriented perpendicular to the weld direction, which is also the main orientation of the loading stresses applied in K-joints. This paper demonstrates that it is the complex geometry of the K-joint that causes the superposition of critical stresses, making these joints susceptible to fatigue cracking. Therefore, transverse residual stresses play a crucial part in the fatigue crack growth behaviour that applied stresses alone cannot explain.
\end{abstract}

() 2012 Elsevier Ltd. All rights reserved.

\section{Introduction}

Steel bridges are commonly welded structures that are subjected to cyclic loading and may experience fatigue cracking. The joints are the place of high tensile residual stresses caused by the welding process. Combined with high stress concentrations due to the traffic loadings, tensile residual stress is a relevant factor in fatigue crack development [1-3].

Residual stress magnitude may reach a high proportion of the yield strength $[4,5]$ implying that even under applied compressive cyclic loadings, they can generate tensile internal stresses. This means that they are able to suppress crack closure, thus resulting in crack propagation rates similar to those under applied tension. It has been observed that the residual stress variation with depth strongly influences the crack propagation path and the crack growth rate. Therefore it is necessary to use residual stress characterisation methods such as neutron diffraction which can probe the triaxial residual stress state as a function of depth [6-8].

In 2000, an extensive review of biaxial residual stress data in tubular joints was made by Stacey [9] on pipe-to-plate joints,

\footnotetext{
* Corresponding author. Tel.: +41 2169324 25; fax: +41 2169328.

E-mail addresses: claire.acevedo@a3.epfl.ch (C. Acevedo), evans@ill.fr (A. Evans), alain.nussbaumer@epfl.ch (A. Nussbaumer).
}

tubular T-joints and Y-joints. This showed that mean longitudinal residual stresses (stresses parallel to the weld direction) never exceeded the material yield stress by more than 20 MPa. Furthermore, mean transverse residual stresses were never seen to exceed $65 \%$ of the yield stress. In general, it is the transverse stress distribution that is of the most interest, as the principal stresses due to the applied loads also tend to be oriented perpendicularly (or transversely) to the weld direction. Triaxial local residual stresses of tubes have only been obtained by a few researchers, Mochizuki [10] being one among them. He was able to determine the local residual stress distribution using neutron diffraction measurements, but he did it only in butt joints between tubes. The triaxial residual stress state and its distribution in depth are not known for tubular Kjoints. They are necessary to explain why cracks occur at the chord crown toe locations independently of the applied stress field.

In order to fill this gap, experimental studies were carried out on tubular K-joints. The main objective was to quantify the triaxial residual stress field in terms of magnitude and variability in the vicinity of the brace-chord weld intersection. Neutron diffraction was chosen for these measurements because it is the only technique providing the triaxial stresses through the wall chord thickness. This measurement technique is not destructive; however, for measurements in thick specimens like K-joints, windows were cut far from the measurement area to prevent significant attenuation of the neutron beam. Due to a limited number of measurement points, 
the adopted strategy was to measure points on a through-thickness plane situated in the gap region of the K-joint (see Fig. 1 ). This plane is known to correspond to one of the principal residual stress planes in surface and to include the starting point of the crack growth. In addition, the measurements presented hereafter were performed on joint samples with two different large wall thicknesses (20 or $30 \mathrm{~mm}$ ) and different loading histories (as-welded or fatigue-tested). Hence, a second aim of this experimental investigation was to identify some possible consequences of these changes: the thickness effect which may influence the stress distribution and the fatigue cycles which may relax and redistribute the residual stresses.

\section{Neutron diffraction setups}

Uncharged neutron particles can penetrate to depths up to $3-6 \mathrm{~cm}$ from the surface for steel materials using neutron diffraction instruments presented in this paper, whereas other techniques cannot. Even high-energy synchrotron X-rays are more limited in depth penetration [11]. This enables measurement of residual strains in tubular joints with large wall thicknesses of $20-30 \mathrm{~mm}$.

By reorienting the sample, it is possible to measure strain values in three or more directions, allowing the calculation of residual stresses. Therefore, neutron diffraction (ND) is a powerful tool to provide through-thickness residual stresses. Its popularity has been ever growing since it was standardized by ISO/TTA in 2001 [12].

\subsection{Physical principle}

Neutron diffraction is used to provide information on the lattice spacing $d_{\mathrm{hkl}}$. In order to simplify notation, $d_{\mathrm{hkl}}$ is replaced by $d$ hereafter. Under stress, the atomic lattice deforms, consequently the lattice acts as a strain gauge.

The $d$ spacing can be obtained by using Bragg's law (equation (1)). This law expresses the supplementary path travelled by the deepest wave as $2 d \sin \theta$. The interference is constructive if the difference of phase between the two paths is a multiple of $2 \pi$, thus if the supplementary path is a multiple of the wavelength. Hence, for a constructive interference, an increase of the $d$ spacing implies a decrease of $\theta$.

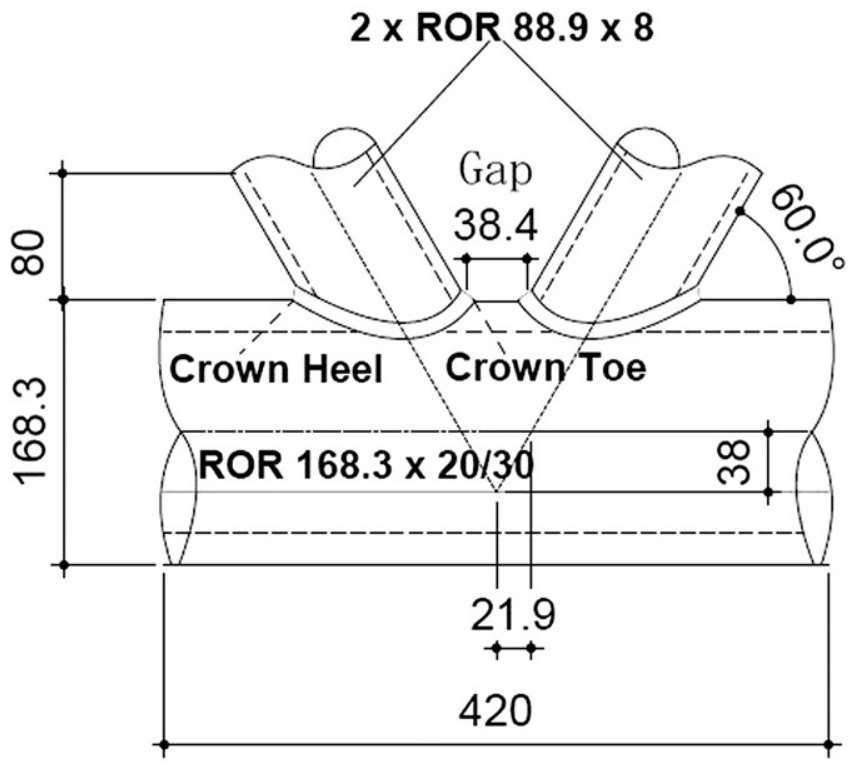

Fig. 1. Schematic of the K-shape welded joint (dimensions in $\mathrm{mm}$ ). $n \lambda=2 d \sin \theta$

where $\lambda$ is the wavelength, $n$ is an integer, $d$ is the spacing between the planes of the atomic lattice and $\theta$ is the angle between the incident and scattering beams.

Therefore, for a fixed wavelength and knowing $d_{0}$ or $\theta_{0}$ (under stress-free conditions), elastic strain can be calculated as follows:

$\varepsilon=\frac{d-d_{0}}{d_{0}}=-\cot \theta \cdot\left(\theta-\theta_{0}\right)$

The orientation of principal residual stresses in the surface were known from previous hole-drilling measurements [13]. These three directions $(x, y, z)$ were assumed to be the principal ones for the indepth strain measurements. Residual stresses can then be calculated using generalised Hooke's law [14]:

$$
\begin{aligned}
& \sigma_{x}=\frac{E}{1+\nu} \cdot\left(\varepsilon_{x}+\frac{\nu}{1-2 \nu} \cdot\left(\varepsilon_{x}+\varepsilon_{y}+\varepsilon_{z}\right)\right) \\
& \sigma_{y}=\frac{E}{1+\nu} \cdot\left(\varepsilon_{y}+\frac{\nu}{1-2 \nu} \cdot\left(\varepsilon_{x}+\varepsilon_{y}+\varepsilon_{z}\right)\right) \\
& \sigma_{z}=\frac{E}{1+\nu} \cdot\left(\varepsilon_{z}+\frac{\nu}{1-2 \nu} \cdot\left(\varepsilon_{x}+\varepsilon_{y}+\varepsilon_{z}\right)\right)
\end{aligned}
$$

where $E$, standing for $E_{\mathrm{hkl}}$, is the Young's modulus, $\nu$, standing for $\nu_{\mathrm{hkl}}$, is the Poisson's ratio.

\subsection{Specificities of the POLDI at the Paul Scherrer Institute (PSI) and of the SALSA at the Institute Laue-Langevin (ILL)}

The presented work was conducted on two different neutron diffraction instruments, POLDI (PSI) and SALSA (ILL).

The multiple Pulse-OverLap-DIffractometer POLDI uses the time-of-flight (TOF) method to measure the lattice spacing. This is achieved by measuring the time passed from the emission of a neutron from a rotating chopper to the time at which it is detected. This allows for the calculation of the wavelength $\lambda$ and the determination of the $d$ at a fixed diffraction angle $\theta$ [15].

In contrast, the Strain Analyser for Large and Small scale engineering Applications SALSA is a monochromatic strain diffractometer. It uses a double-focussing monochromator to select a single wavelength of neutrons from a continuous flux of thermal neutrons [16]. Therefore the lattice spacing is calculated by measuring the variation in lattice spacing $d$. To define the sampling volume, radial collimator optics were utilised delimiting a $2 \times 2 \mathrm{~mm}^{2}$ cross section. The sample is fixed on the hexapod, a platform lying on six servo-hydraulic jacks allowing the achievement of accurate translational and rotational movements.

In Table 1, the main features of POLDI and SALSA are summarized. In PSI, the lattice spacing is obtained through the wavelength whereas at ILL, it is determined through the scattering angle.

Measurements are comparable because we only used the (211) deflection with a fixed diffraction angle of $90^{\circ}$. At $90^{\circ}$ the (211) refection is intense enough compared to other reflections.

Table 1

Main features of POLDI and SALSA.

\begin{tabular}{lll}
\hline & POLDI (PSI) & SALSA (ILL) \\
\hline Wavelength $(\lambda)$ & $1.1-5 \AA$ & $1.64 \AA$ (á-Fe) \\
Scattering angle $2 \theta$ & $90 \pm 15^{\circ}$ & $90 \pm 5^{\circ}$ \\
Flux at sample pos. $\left(10^{6} \mathrm{n} / \mathrm{s} / \mathrm{cm}^{2}\right)$ & 6 & 50 \\
Resolution $\left(10^{-3}\right)$ & $1-2$ & 2 \\
Meas. time (in surface, gauge v. $\left.2 \times 2 \times 2 \mathrm{~mm}^{3}\right)$ & $30 \mathrm{~min}$ & $5 \mathrm{~min}$ \\
\hline
\end{tabular}


Table 2

Test samples characteristics and dimensions in $\mathrm{mm}$.

\begin{tabular}{lllll}
\hline Sample no. & ND institute & Loading history & Chord dim. & Brace dim. \\
\hline AW-30 & PSI & As-welded & $168.3 \times 30$ & $88.9 \times 8$ \\
FAT-20 & ILL & Fatigue-tested & $168.3 \times 20$ & $88.9 \times 8$ \\
FAT-30 & PSI & Fatigue-tested & $168.3 \times 30$ & $88.9 \times 8$ \\
\hline
\end{tabular}

First experiments were conducted at POLDI on a $30 \mathrm{~mm}$ thick sample. However, the flux intensity proved to be insufficient for our geometric configuration. The following specimens were cut to facilitate measurements. The high flux and low background noise of SALSA permitted more efficient and faster measurements of lattice strain at great depths. Due to limitation of beam time available at SALSA, measurements on the third sample were carried out at POLDI, this time with windows cut in the sample in order to minimise the neutron path length into the material.

\section{Experimental description}

\subsection{Test samples}

The samples investigated were welded joints fabricated and welded by a steel bridge fabricator in the same conditions as real bridges. The first sample AW-30 was as-welded (untested) whereas the others (FAT-20 and FAT-30) were cut from Circular Hollow Section (CHS) truss beams, $9 \mathrm{~m}$ long and $2 \mathrm{~m}$ high. These truss beams were previously tested under fatigue, however, the joints cut from them were the only non-cracked joints. All together, ND measurements were performed on three joints. These joints are identified and illustrated in Table 2 and in Fig. 2.

Each sample is composed of part of the chord with two braces branches welded onto it, forming a K-joint, schematically shown in Fig. 1. Truss CHS members are made of grade S355J2H carbonmanganese (C-Mn) steel with a nominal yield strength of 355 MPa. The mechanical properties of the steel, which has a ferrite-pearlite structure, are presented in Table 3.

The full penetrated weld was made by using the Flux cored metal-arc welding process (MAG process 136). For each joint, independently of CHS wall thickness, seven weld passes from the crown heel to the crown toe were produced (see Fig. 1). The process specifications are summarized in Table 4.

The nominal chemical composition of the Base Metal (BM) and the Fusion Zone (FZ) are presented in Tables 5 and 6 . In Table 5, the effective average values were also calculated based on measured data given by the tube producer.
Table 3

S355 mechanical properties.

\begin{tabular}{llr}
\hline Mech. properties & Nominal values & Effective aver. values \\
\hline Young's modulus $E(\mathrm{MPa})$ & 210,000 & \\
Poisson's ratio $\nu$ & 0.3 & \\
Yield stress $(\mathrm{MPa})$ & & \\
For $t \leq 16 \mathrm{~mm}$ & Min 355 & 385 \\
For $16 \mathrm{~mm}<t \leq 40 \mathrm{~mm}$ & Min 345 & 553 \\
Tensile strength (MPa) & Min 470-Max 630 & 25 \\
Elongation $(\%)$ & Min 22 & 127 \\
Impact energy at $-20{ }^{\circ} \mathrm{C}(\mathrm{J})$ & Min 27 \\
\hline
\end{tabular}

\subsection{Microstructure}

Due to the welding process, the microstructure in a zone of Base Metal close to the weld, or Fusion Zone, is altered by heat transfer. In this Heat Affected Zone (HAZ), martensite-austenite constituents are formed. It is precisely in the HAZ that the crack initiates because of contribution of stress concentration, metallurgical discontinuities and high number of dislocations in the HAZ microstructure. The crack then propagates in the BM. As shown in Fig. 3, apart from the first millimetre, the crack profile path is essentially within the BM.

The micrograph presented in Fig. 4 reveals that the microstructure of the studied BM is mainly comprised of ferrite and pearlite grains. The pearlite consists of alternating layers of ferrite (alpha iron) and cementite $\left(\mathrm{Fe}_{3} \mathrm{C}\right)$. Globally, ferrite represents the major fraction of volume, even in the HAZ.

\subsection{Experimental method}

The measurements were made following the guidelines outlined in the ISO/TTA standard [12], including the choice of reflection, calculation of strains and stresses and procedures for alignment.

\subsubsection{Stress-free reference samples}

To calculate the elastic strain $\varepsilon$ (equation (2)), a stress-free reference either in $d$ spacing or diffraction angle $d_{0}$ or $\theta_{0}$ is required. In order to relax residual stresses, small cubes were cut by electro-discharge machining (EDM) for PSI samples and with a diamond blade for ILL sample. These methods for sectioning were chosen to minimise the chance to induce new residual stresses.

By EDM, two sets of stress-free samples were machined to measure the $d_{0}$ spacing in the Heat Affected Zone (HAZ) and also in the Base Metal (BM). For the first set in the HAZ, two cubes of

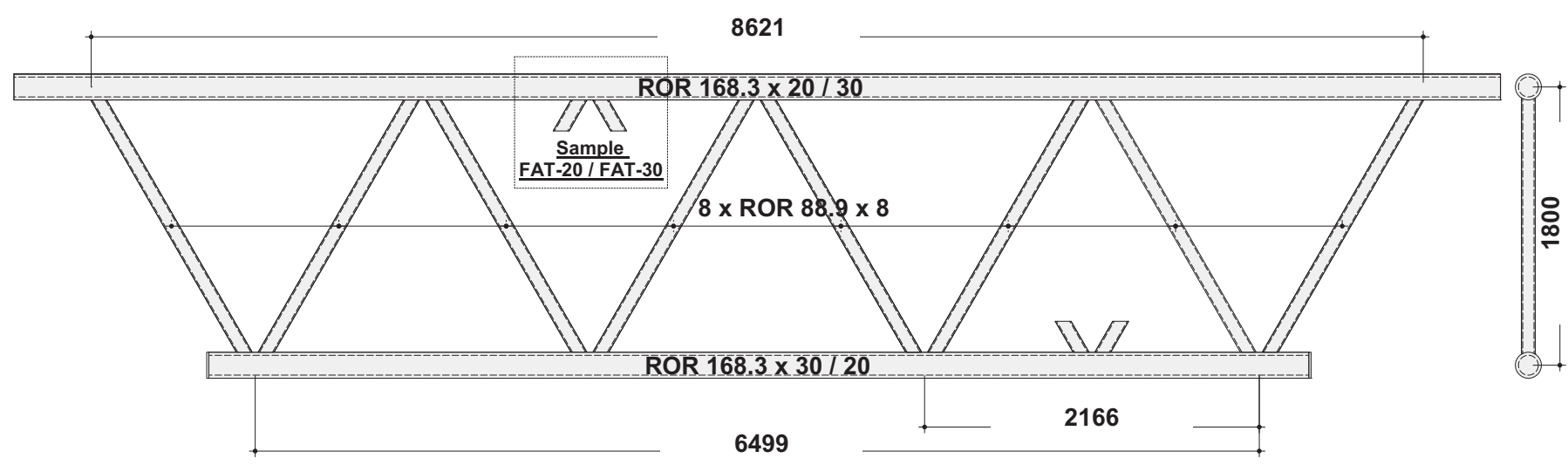

Fig. 2. Truss beams with fatigue-tested joints (FAT-20 from beam S6 and FAT-30 from beam S7) devoted to neutron diffraction measurements (dimensions in mm). 
Table 4

Welding specifications.

\begin{tabular}{ll}
\hline Electrical wire type & Filarc $1.4 \mathrm{~mm}$ \\
Welding current $(\mathrm{A})$ & 270 \\
Arc voltage $(\mathrm{V})$ & 30 \\
Arc travel speed $(\mathrm{cm} / \mathrm{min})$ & 33 \\
Interpass temperature $\left({ }^{\circ} \mathrm{C}\right)$ & $\leq 250$ \\
Degree of efficiency & 0.8 \\
Range of thicknesses $(\mathrm{mm})$ & $8-30$ \\
Number of passes & 7 \\
\hline
\end{tabular}

dimension $1 \mathrm{~mm} \times 1 \mathrm{~mm} \times 1 \mathrm{~mm}$ were cut out and for the second set in the BM, four cubes of dimension $2 \mathrm{~mm} \times 2 \mathrm{~mm} \times 2 \mathrm{~mm}$ were taken at different depths from the surface (centers of cubes are at $1.5 \mathrm{~mm}, 4 \mathrm{~mm}, 7 \mathrm{~mm}$ and $10 \mathrm{~mm}$ depth). With the diamond blade, straight cuts were made at $3 \mathrm{~mm}$ from the surface to form a stick (section $3 \mathrm{~mm} \times 8 \mathrm{~mm}$ ) containing a part of the BM and a part of the HAZ. Results of measurement conducted on stress-free samples are presented in Section 3.4.1.

\subsubsection{Three measurement directions}

In order to measure strain in a certain direction, the sample was oriented so that the bisector between the incident and the diffracted neutron beam coincided with that direction.

For the sample tested, it was planned to measure transverse strain (perpendicular to the weld direction), longitudinal strain (parallel to the weld direction) and radial strain (in the radial direction of the tube) in the weld toe vicinity. By reorienting the sample, strain values were obtained in the three principal directions (see Fig. 5). The mean scattering angle is approximately of $2 \theta=90^{\circ}$.

In order to obtain the spatial resolution required to measure the residual strain variation through tube thickness, the choice of the gauge volume (region of intersection of the incident and diffracted beams) had to be determined carefully. The gauge volumes used are summarized in Table 7. They were chosen to measure with sufficient statistics within a reasonable period of time.

Since the residual strain obtained is the mean value of the distribution over the sampling gauge volume $\left(\mathrm{mm}^{3}\right)$, the highest strain value located at a stress concentration will always be underestimated.

\subsubsection{Diffraction}

In a polycrystal, the diffraction peak gives the average of the strains in the different types of grains present in the gauge volume. However, the response of diffraction peaks for each crystallographic lattice plane may be different from the global response. Since measuring multiple reflections is not always feasible, the lattice plane reflection which fits best the global macrostresses has to selected. The elastic response of the polycrystal is calculated from single-crystal constants [17].

During the experiments, residual strains were measured with the (211) Bragg reflection, presenting the advantage of achieving a $90^{\circ}$ diffraction angle for a wavelength of $1.6 \AA$ A. However, to relate

Table 5

Steel S355J2H Base Metal composition (\% of weight).

\begin{tabular}{lll}
\hline $\begin{array}{l}\text { Elements } \\
\text { (Base material) }\end{array}$ & $\begin{array}{l}\text { Nominal max. mass\% } \\
(\text { EN 10210) }\end{array}$ & Effective average mass\% \\
\hline Carbon C & $\leq 0.18$ & 0.17 \\
Silicon Si & $\leq 0.55$ & 0.26 \\
Manganese Mn & $\leq 1.60$ & 1.36 \\
Phosphorus P & $\leq 0.030$ & 0.01 \\
Sulphur S & $\leq 0.030$ & 0.004 \\
\hline
\end{tabular}

Table 6

Weld composition (\% of weight).

\begin{tabular}{lll}
\hline Elements (weld-fusion zone) & Nominal max. mass\% & Nominal min. mass\% \\
\hline Carbon C & 0.18 & 0.08 \\
Silicon Si & 0.9 & 0.33 \\
Manganese Mn & 1.75 & 1.58 \\
Phosphorus P & 0.03 & 0.02 \\
Sulphur S & 0.03 & 0.01 \\
\hline
\end{tabular}

this measured strains to the macrostresses of interest, it must be assumed that the (211) atomic plane is weakly affected by intergranular strains, or in other words, its response is linear and independent of the regime (elastic or plastic) [11,18]. The ISO/TTA standard [12] recommends suitable lattice planes for several crystal structures. For the body-centered cubic of ferrite, the lattice planes (110) and (211) are recommended. Therefore, the (211) reflection was a reasonable choice for reliable and efficient measurement of strain in S355J2H steel.

The Young's modulus, $E$, and the Poisson's ratio, $\nu$, have shown to be close between the (211) atomic plane $\left(E_{211}=220,000 \mathrm{MPa}\right.$ and $\left.\nu_{211}=0.28\right)[19]$ and the bulk S355J2H steel $(E=210,000 \mathrm{MPa}$ and $\nu=0.3$ ). These values are available in transverse, longitudinal and radial directions. The S355J2H moduli values were used for stress calculation.

\subsection{Data analysis}

\subsubsection{Stress-free reference values}

$d_{0}$ was measured on both instruments and the difference between the BM and HAZ in both cases was less than $100 \mu \varepsilon$. Therefore the $d_{0}$ measured in the BM was used throughout. The POLDI and SALSA used their own respective $d_{0}$ due to differences in calibration.

It has to be noted that these reference values, expected to be different in the BM and HAZ, are very close. Since the sample did not seem to be textured (in a material textured by yielding, the atomic planes are not distributed randomly but they present a preferred orientation), it is assumed that the $d_{0}$ spacing is the same in the three principal directions. The value of $d_{0}=1.1707 \AA$ or $2 \theta_{0}=89.493^{\circ}$ was kept for strain calculation since the Base Metal is the main part of the sample.

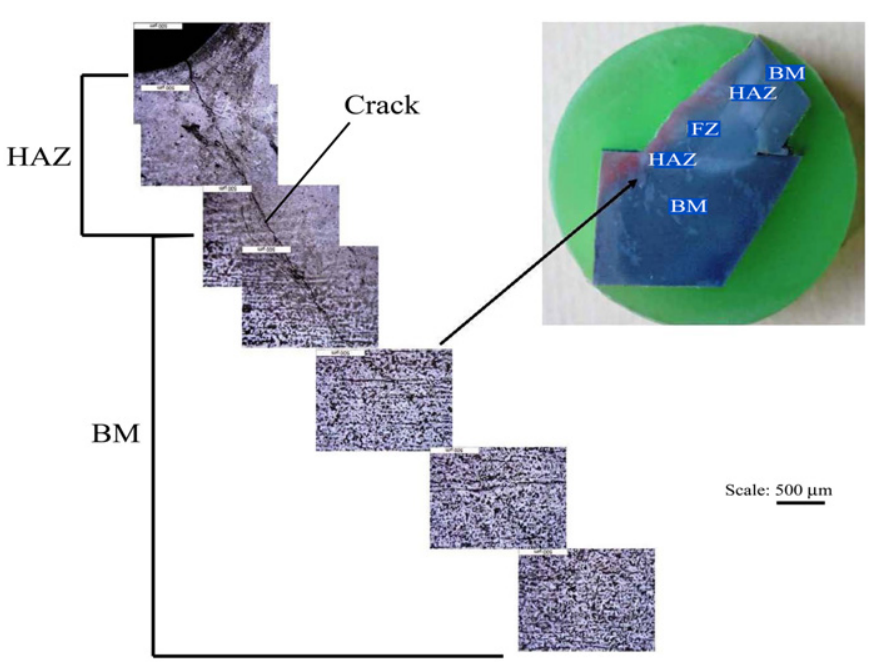

Fig. 3. A typical example of the crack path in one of the joints investigated. The crack surface is in reality curved in two directions. 


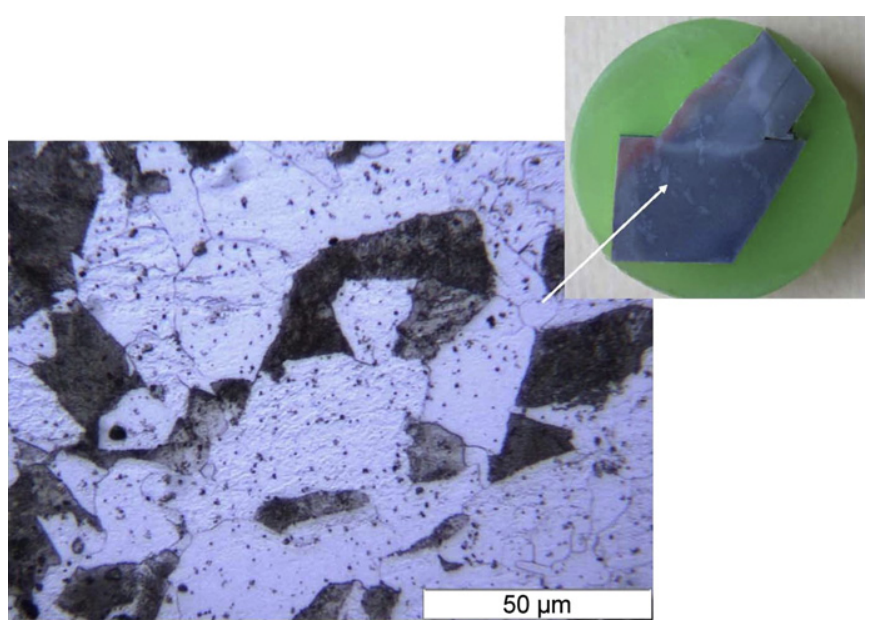

Fig. 4. Microstructure of $\mathrm{S} 355 \mathrm{~J} 2 \mathrm{H}$ in the as-delivered state as revealed by optical microscopy. It shows a ferritic and pearlitic microstructure. Large light grey areas are ferrite (alpha iron) crystals and large black areas are colonies of pearlite (composed of ferrite and cementite $-\mathrm{Fe}_{3} \mathrm{C}$ ).

\subsubsection{Strain measurements}

As explained in Section 3.3.3, the (211) peak was used for strain calculation. The lattice spacing in the K-shape joint sample was measured at different locations positioned in a line between the two welds. This line is situated in the gap region of the K-joint. At each location a depth scan has been made comprising points at several depth distances from the surface.

\subsubsection{Beam path length limit}

For the first series AW-30, strain was obtained only in the radial direction. Two shortcomings were encountered for the longitudinal and transverse directions (dir. 2 and 3). First, the path length of the beam through the $30 \mathrm{~mm}$ thick tube exceeded the maximum feasible limit of POLDI for neutrons in steel $(\approx 30 \mathrm{~mm})$. Secondly the presence of the opposite weld caused the neutron a

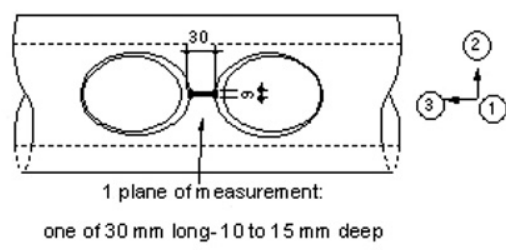

The plane of measurement

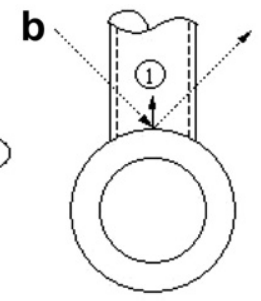

radial direction (dir. 1)

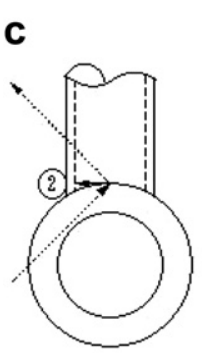

longitudinal direction (dir. 2)

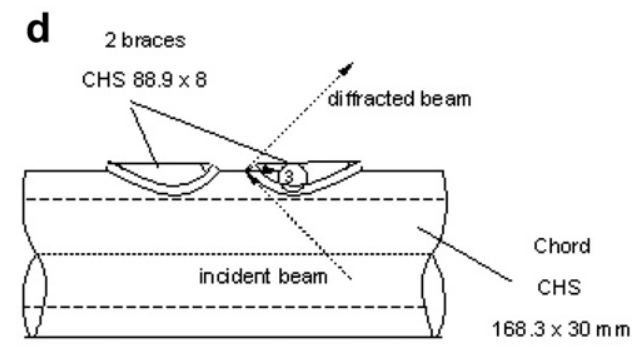

transverse direction (dir. 3)

Fig. 5. Plane and directions of measurements.

Table 7

Gauge volumes chosen for each test sample.

\begin{tabular}{llc}
\hline Sample no. & ND institute & Gauge volume $\left[\mathrm{mm}^{3}\right]$ \\
\hline AW-30 & PSI & $2 \times 2 \times 2.5$ \\
FAT-20 & ILL & $2 \times 2 \times 2$ \\
FAT-30 & PSI & $3.8 \times 3.8 \times 3.8$ \\
\hline
\end{tabular}

beam to be further attenuated. For this reason, in the second and third series FAT-20 and FAT-30, windows were cut in the tube, away from the region of the weld, in order to avoid the neutron penetration of both walls. Note also that at ILL, the maximum path length limit is $60 \mathrm{~mm}$. This is due to a drastically lower background.

a

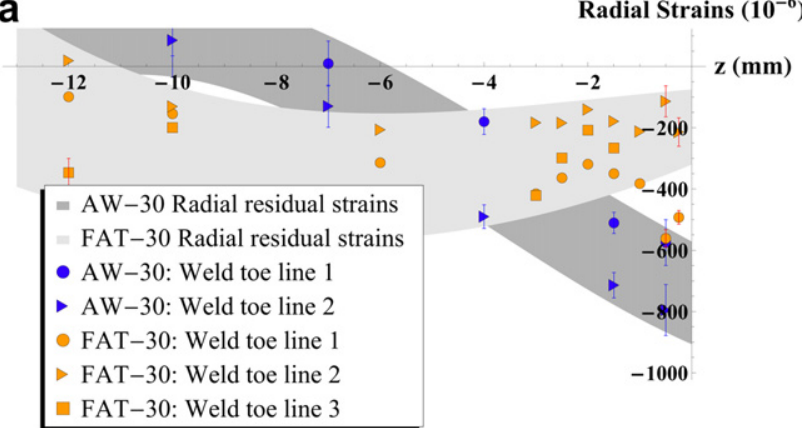

Shakedown effect study. Representation of radial residual strains in function of depth $\mathrm{z}$ for the as-welded sample (AW-30) and the fatigue-tested sample (FAT-30), both with chord wall thicknesses of $30 \mathrm{~mm}$.

b

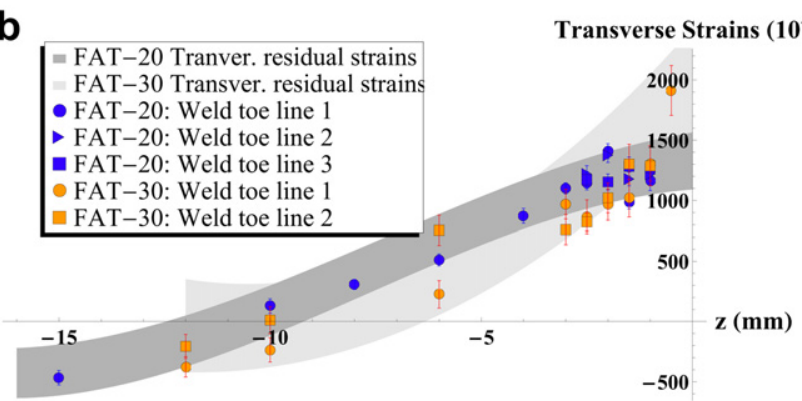

Size effect study. Representation of transverse residual strains in function of depth $\mathrm{z}$ for the fatigue-tested samples (FAT-20 and FAT-30).

$\mathbf{C}$

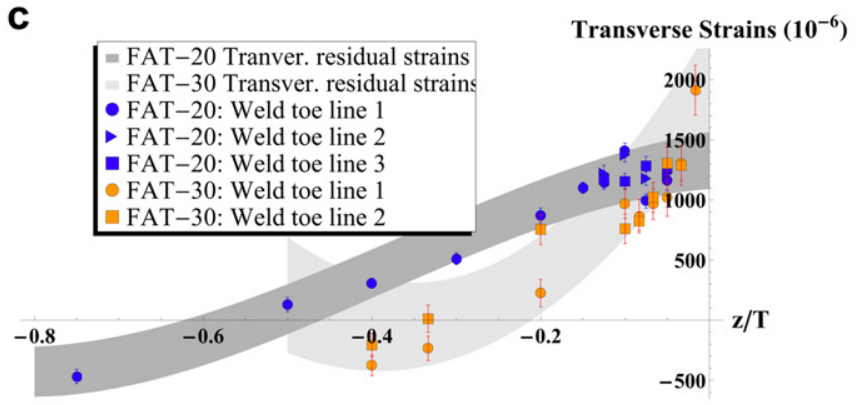

Size effect study. Representation of transverse residual strains in function of depth over thickness $\mathrm{z} / \mathrm{T}$ for the fatigue-tested samples (FAT-20 and FAT-30).

Fig. 6. Shakedown and size effect studies. Residual strain data points with error bars and residual strain envelopes. Measurement points are taken along vertical lines underneath the weld toe. 
a

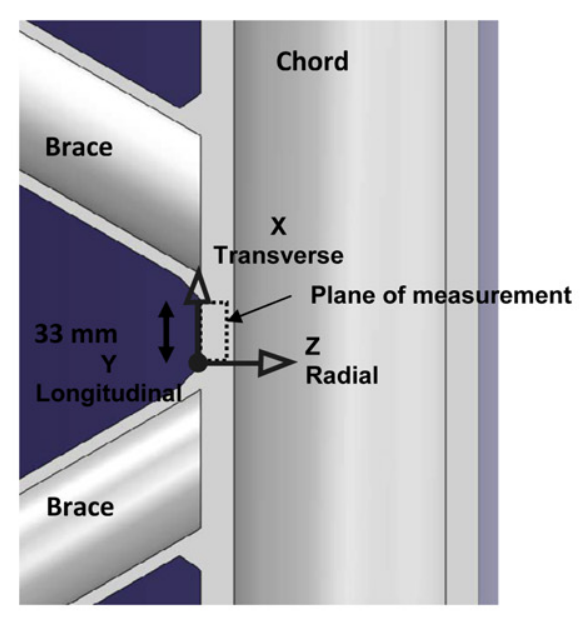

Plane of measurement

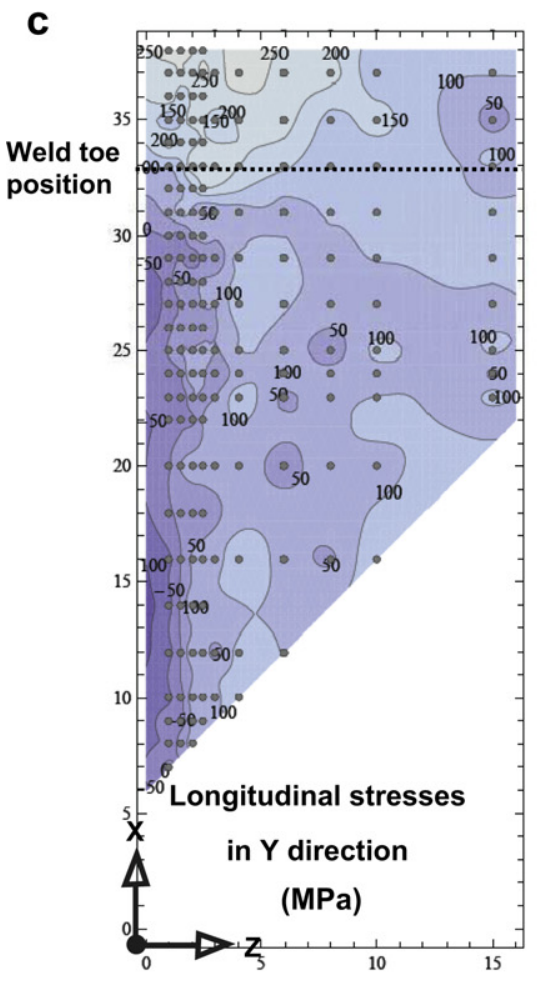

Stresses in the longitudinal direction

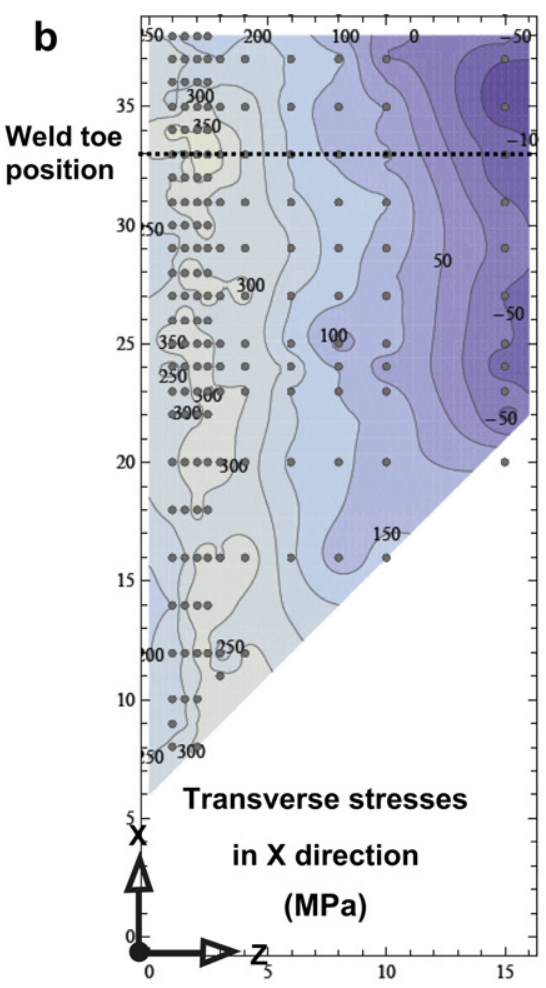

Stresses in the transverse direction

Stresses in the radial direction
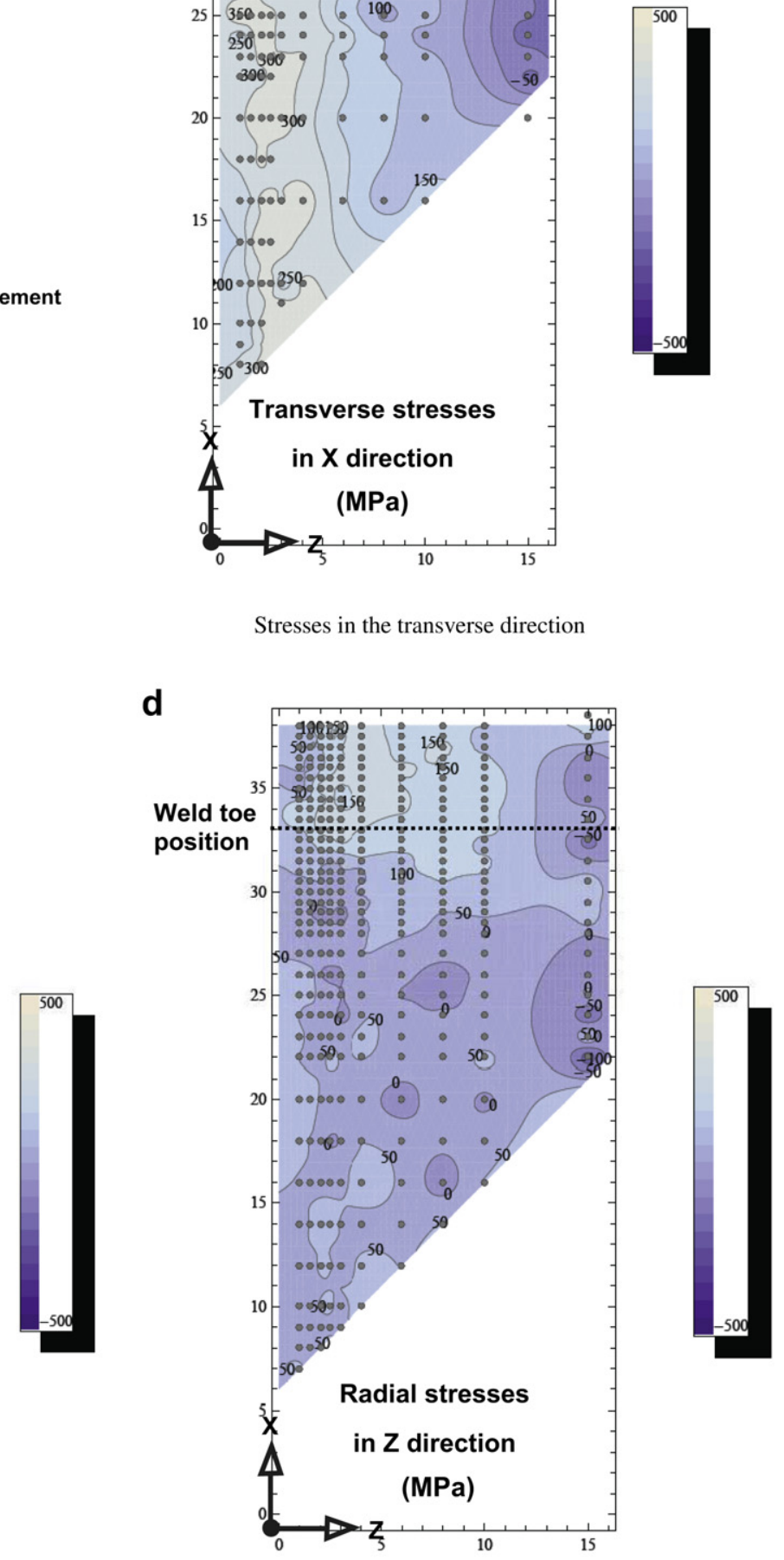

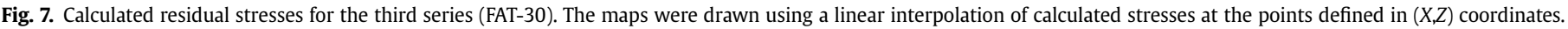




\section{Results and discussion}

Strains were calculated using equation (2) and the stress-free lattice values given in Section 3.4.1. The measurement uncertainty that is quoted in the data sets (Fig. 6) has been derived from the fitting uncertainties in the analysis of the raw neutron data by normal error propagation. Measurements were repeated at the same position to assess the systematic error, the magnitude of which remained lower than the statistical error of the fit. The error calculated from the fit is given with respect to $d$ at PSI and with respect to $\theta$ at ILL. Thus, the error related to strain is deduced and reported on each point in Fig. 6. The error related to stress is then calculated.

As shown in Table 2, two parameters differ in the samples characteristics: the chord wall thicknesses $(20$ or $30 \mathrm{~mm}$ ) and the loading history (as-welded or fatigue-tested). Hence, by comparing results for samples AW-30 and FAT-30, a possible shakedown effect of fatigue cycles can be evaluated. Moreover, the comparison of samples FAT-20 and FAT-30 should provide information on size effects influence.

\subsection{Shakedown effect}

In high-cycle fatigue under constant amplitude, the first stress cycles can induce elastic shakedown, meaning that local plastic deformation may cause a redistribution and a relaxation of residual stresses. The modification of the residual stress level is particularly linked with the yield behaviour and the geometrical conditions such as the chord wall thickness [20].

In order to identify a possible peak stress relaxation and redistribution during the first fatigue cycles, strains at different positions underneath the weld toe from the as-welded (AW-30 series) and fatigue-tested (FAT-30) samples are compared in Fig. 6. The fatiguetested sample was part of a truss specimen subjected to 110,000 cycles with a maximum applied stress around $-17 \mathrm{Mpa}$ and a minimum applied stress around $-1 \mathrm{MPa}$ in the brace side of the chord. These fatigue experiments are described in more detail in [21].

Since only radial strains were obtained from the first series, comparisons are based on this strain direction. It can be seen on Fig. 6 that indeed some relaxation of the radial strain field occurs within the first $4 \mathrm{~mm}$, resulting in a redistribution of strain magnitude along the depth in the chord wall thickness. However, this conclusion cannot be extended to transverse and longitudinal strains even if this shakedown effect is often encountered for highcycle fatigue with high stress range [9]. The magnitude of any relaxation in these directions remains to be confirmed.

\subsection{Size effect}

A study concerning the influence of the sample thickness on the residual stress distribution has also been conducted to identify if the residual stress distribution function is best related to $z / T$ or to $z$ (where $z$ is the depth below the surface of chord wall and $T$ the chord wall thickness). Comparison between neutron diffraction transverse strains in the weld toe vicinity, for a chord wall thickness of $20 \mathrm{~mm}$ (FAT-20 series) and of $30 \mathrm{~mm}$ (FAT-30 series) is presented in Fig. $6 \mathrm{~b}$ and $\mathrm{c}$.

It seems that the transverse strain distribution is better related to $z$ than to $z / T$. Since the transverse strain distributions versus depth $z$ are quite similar for a $20 \mathrm{~mm}$ or a $30 \mathrm{~mm}$ thick wall, the authors chose to consider it as a non-proportional size effect. The reason is that the welding process, the wire size and the heat input were the same for all samples. It is true however that distributions are not perfectly superimposed and the trend is not so clear for longitudinal and radial strains. This must be confirmed by further measurements.

\subsection{Residual stresses maps}

Based on the previous considerations, the second and third series of measurements are used to estimate the residual stress distribution. Since more data points are available from the measurements at ILL, these results allow for the construction of residual stress $2 \mathrm{D}$ maps (Fig. $7 \mathrm{~b}-\mathrm{d}$ ).

The transverse direction is perpendicular to the weld, the longitudinal direction is parallel to the weld and the radial direction is the depth direction. Points of measurement were taken along the longitudinal tube axis, along a line in the gap between the two welds and depth scans were made (see plane of measurement in Fig. 7a). A thousand points were used to draw these maps.

Fig. 8 gives another representation of the residual stress distribution in the vertical depth under the weld toe. Discrepancies between samples FAT-20 and FAT-30 appear in the surface area (from 1 to $3 \mathrm{~mm}$ depth) and for a depth below $10 \mathrm{~mm}$ and may be attributed to the effect of the wall thickness. Although the results indicate that increasing the wall chord thickness tends to decrease the transverse residual stress magnitude at the surface, care should be exercised since the statistical error is larger for stresses measured in the sample FAT-30 (thickness of $30 \mathrm{~mm}$, PSI) than in sample FAT-20 (thickness of $20 \mathrm{~mm}$, ILL). This is mainly because of the longer beam path length, leading to poorer counting statistics (lower peak to background ratio).

Transverse Stresses (MPa)

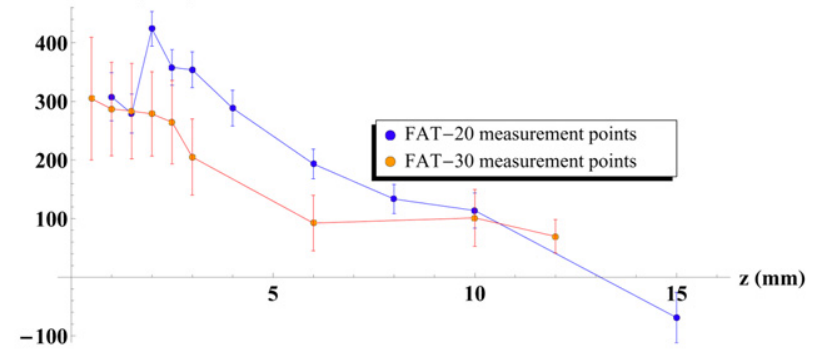

Longitudinal Stresses (MPa)

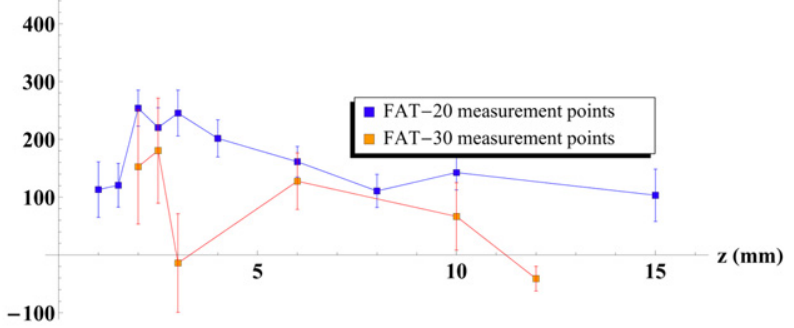

Radial Stresses (MPa)

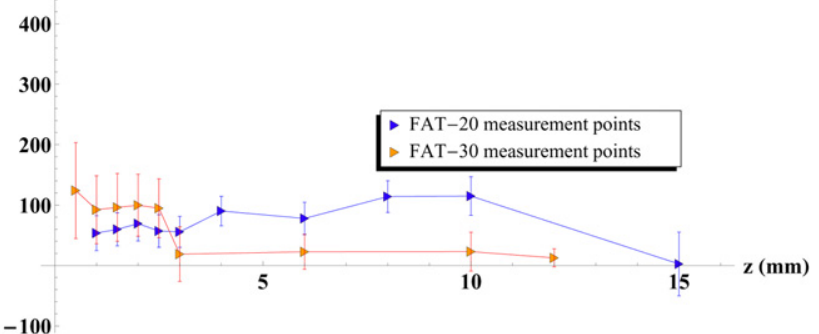

Fig. 8. Calculated data points and error bars of residual stresses versus depth along a vertical line underneath the weld toe (fatigue-tested samples FAT-20 and FAT-30). Transverse, longitudinal and radial directions are respectively the principal direction I, II and III in the surface of the chord. 
Fig. $7 \mathrm{~b}$ and c show that tensile transverse residual stresses are close to or even reach the effective yield stress value of $385 \mathrm{Mpa}$ (Table 3 ) in the area around the weld toe (350-420 MPa for a depth between 2 and $3 \mathrm{~mm}$ ) and are greater than longitudinal ones, which is not the case for tubular butt welds [9]. Moreover, this particular orientation of the largest residual stresses is also the orientation of the externally applied stresses, as a consequence they will superimpose in a detrimental way. In addition, the magnitude of the transverse residual stress remains high in the gap region due to a restraining effect between braces. This effect induces tensile residual stresses over most of the wall thickness and in the whole gap region. Note that these residual stress maps are not self-equilibrated in section since only a localised region was observed. The geometry of the K-joint is responsible for the high applied stresses and for high residual stresses due to welding in the same region, which is critical for fatigue.

\section{Conclusions}

The residual strain (and stress) field in a welded bridge joint made of C-Mn steel has been evaluated using the POLDI time-offlight diffractometer at the Paul Scherrer Institute and the SALSA diffractometer at the Institute Laue-Langevin.

Neutron diffraction proved to be a powerful and reliable method to collect large quantities of data from the surface to a depth of $15 \mathrm{~mm}$ in a complex geometry (welded tubular K-joints). Thanks to this technique, triaxial measurements of residual strain field were possible. Results have shown that transverse residual stress magnitude is close to or equal to the yield strength of the steel $\mathrm{S} 355 \mathrm{~J} 2 \mathrm{H}$ and is greater than in the longitudinal direction. This distribution is drastically different from those of the more common tubular butt welded joints. This particular orientation of the greater residual stresses is critical because it is also the orientation of the externally applied stresses. Moreover, experiments have led to another unexpected result, since residual stress magnitudes remain high in the gap region due to a restraining effect between braces. Therefore, the fatigue cracks observed in complex K-joint geometry may be explained by combining the transverse residual stresses with the applied stresses. The geometry of the K-joint is responsible for the high applied stresses and for high residual stresses due to welding in the same region which is critical for fatigue. Therefore, in this region, taking into account the transverse residual stresses is key in estimating the fatigue strength of K-joint.

Neutron diffraction indicated a probable shakedown effect reducing the residual stress level. This reduction is not proved to occur in three directions, especially in transverse direction. It also revealed the existence of a non-proportional size effect. However these last points have to be confirmed respectively by new neutron diffraction investigations and by numerical parametric studies [22].

\section{Acknowledgements}

This research is part of a $\mathrm{PhD}$ project funded by the Swiss National Science Foundation (SNF). The authors would like to acknowledge Vallourec and Mannesmann Deutschland GmbH for supplying the tubes and Zwahlen and Mayr S.A. for fabricating the $\mathrm{K}$-joints as well as the large scale tubular truss beam specimens. Neutron diffraction experiments were carried out at the Paul Scherrer Institute (POLDI) and the Institute Laue-Langevin (SALSA). Thanks are due to Dr. D.J. Hughes from the ILL for its know-how in neutron diffraction measurements.

\section{References}

[1] Maddox SJ. Fatigue strength of welded structures. Abington Publ.; 1991.

[2] Gurney T. Fatigue of welded structures. Cambridge Univ. Press; 1979.

[3] Mirzaee-Sisan A, Truman CE, Smith DJ, Smith MC. Interaction of residual stress with mechanical loading in a ferritic steel. Eng Fract Mech 2007;74(17): 2864-80.

[4] McClung RC. A literature survey on the stability and significance of residual stresses during fatigue. Fatig Fract Eng Mater Struct 2007;30:173-205.

[5] Bouchard PJ. Residual stresses in lifetime and structural integrity assessment. Pergamon: Buschow KHJ, Encycl. of Materials Science and Technology; 2001.

[6] Withers PJ, Bhadeshia HKDH. Residual stress part 1 - measurement techniques. Mater Sci Technol 2001;17:355-65.

[7] Fitzpatrick M, Hutchings M, Withers P. Separation of macroscopic, elastic mismatch and thermal expansion misfit stresses in metal matrix composite quenched plates from neutron diffraction measurements. Acta Mater 1997; 45(12):4867-76.

[8] Holden TM, Clarke AP, Holt RA. Neutron diffraction measurements of intergranular strains in monel-400. Metall Mater Trans A 1997;28(12): 2565-76.

[9] Stacey A, Barthelemy JY, Leggatt R, Ainsworth R. Incorporation of residual stresses into the sintap defect assessment procedure. Eng Fract Mech 2000. 67:573-611.

[10] Mochizuki M, Hayashi M, Hattori T. Numerical analysis of welding residual stress and its verification using neutron diffraction measurement. J Eng Mate Technol-Trans ASME 2000;122:98-103.

[11] Hutchings MT, Withers PJ, Holden TM, Lorentzen T. Introduction to the characterization of residual stress by neutron diffraction. Taylor and Francis; 2005.

[12] Webster G. Polycrystalline materials: determination of residual stresses by neutron diffraction. ISO/TTA3 technology trends assessment., vol. 3. International Organization for Standardization; 2001.

[13] Acevedo C, Nussbaumer A. Residual stress estimation of welded tubular kjoints under fatigue loads. In. 12th Int Conf fracture Ottawa Can; 2009.

[14] 21432:2005, D.C.INon destructive testing. Standard test method for determining of residual stresses by neutron diffraction. British Standards Institute; 2006.

[15] Stuhr U, Grosse M, Wagner W. The tof-strain scanner poldi with multiple frame overlap-concept and performance. Mater Sci Eng A-Struct Mater Prop Microstruct Process 2006;437:134-8.

[16] Hughes D, Bruno G, Pirling T, Withers P. First impressions of salsa: the new engineering instrument at ill. Neutron News 2006;17(3):28-32.

[17] Kröner E. Elastic moduli of perfectly disordered composite materials. J Mech Phys Solid 1967;15(5):319-29.

[18] Pang JWL, Holden TM, Mason TE. The development of intergranular strains in a high-strength steel. J Strain Anal 1998;33:373-83.

[19] Wimpory RC, Ohms C. A step towards a complete uncertainty analysis of residual stress determination using neutron diffraction. Mater Sci Forum 2010;638:2487-92.

[20] Krebs J, Kassner M. Influence of welding residual stresses on fatigue design of welded joints and components. Welding in the World 2007;51(7): 54-68.

[21] Acevedo C, Drezet JM, Lefebvre JP, D’Alvise L, Nussbaumer A. Residual stresses in as-welded joints: finite element modeling and neutron diffraction stress measurements. Key Eng Mater 2012;488-489:335-8.

[22] Acevedo C, Nussbaumer A. Effect of tensile residual stresses on fatigue crack growth and s-n curves in tubular joints loaded in compression. Welding in the World 2012;36(1):171-80. 